\title{
Menguji Kekuatan Hubungan Gaya Belajar dengan Hasil Belajar Mahasiwa
}

\author{
Munawarah $1 *$ \\ ${ }^{1}$ Fakultas Ekonomi dan Bisnis Islam, IAIN Bone. Jl. HOS Cokroaminoto, Kab. Bone, Sulawesi \\ Selatan, Indonesia. \\ * Korespondensi Penulis. E-mail: munawarah@gmail.com, Telp: 085242704085
}

\begin{abstract}
Abstrak
Penelitian ini bertujuan untuk mengetahui gaya belajar mahasiswa pada Program Studi Ekonomi Syariah IAIN Bone dan untuk mengetahui hubungan antara gaya belajar dengan hasil belajar Mahasiswa pada Program Studi Ekonomi Syariah IAIN Bone. Penelitian ini adalah penelitian lapangan dengan menggunakan pendekatan kuantitatif. Sampel dalam penelitian ini adalah mahasiswa prodi ekonomi syariah angkatan 2017 yang berjumlah 144 mahasiswa, Teknik pengambilan sampel yang digunakan yaitu metode total sampling yaitu semua subyek yang merupakan mahasiswa prodi ekonomi syariah angkatan 2017 Fakultas Ekonomi dan Bisnis Islam IAIN BONE. Instrumen yang digunakan adalah skala gaya belajar, data yang dikumpulkan dianalisisi menggunakan teknik analisis deskriptif kuantitatif dengan persentase, dan Korelasi Product Moment. Hasil penelitian mengenai hubungan antara gaya belajar dengan hasil belajar mahasiswa pada Program Studi Ekonomi Syariah IAIN Bone, yaitu mahasiswa Prodi Ekonomi Syariah semester IV memiliki gaya belajar yang berbedabeda, yaitu Gaya belajar Visual sebanyak 83 mahasiswa atau 57.6\%, gaya belajar audio sebanyak 21 mahasiswa atau $14,6 \%$, sedangkan gaya belajar kinestetik sebanyak 40 mahasiswa atau $27,8 \%$, dan terdapat hubungan positif dan signifikan antara gaya belajar dengan hasil belajar mahasiswa pada Program Studi Ekonomi Syariah IAIN Bone, koefisien korelasi gaya belajar terhadap hasil belajar sebesar 0,43 dan masuk dalam kategori sedang.
\end{abstract}

Kata Kunci: gaya belajar, hasil belajar

\section{Test the Strength of Learning Style Relationships with Student Learning Outcomes}

\begin{abstract}
This study aims to determine the learning styles of students at the IAIN Bone Sharia Economics Study Program and to determine the relationship between learning styles with student learning outcomes at the IAIN Bone Sharia Economics Study Program. This research is a field research using a quantitative approach. The sample in this study was 2017 students of Islamic Economics Study Program totaling 144 students, the sampling technique used was the total sampling method that is all subjects who were students of 2017 Islamic Economics Study Program Faculty of Economics and Islamic Business IAIN BONE. The instrument used was a scale of learning styles, the data collected were analyzed using quantitative descriptive analysis techniques with percentages, and Product Moment Correlation. The results of research on the relationship between learning styles with student learning outcomes in the IAIN Bone Sharia Economics Study Program, namely students of the fourth semester of Islamic Economics Study Program have different learning styles, namely Visual learning styles of 83 students or $57.6 \%$, audio learning styles of 21 students or $14.6 \%$, while kinesthetic learning styles are 40 students or $27.8 \%$, and there is a positive and significant relationship between learning styles with student learning outcomes in the IAIN Bone Sharia Economics Study Program, the correlation coefficient of learning styles to learning outcomes is 0,43 and in the medium category.
\end{abstract}

Keywords: learning style, learning outcomes 


\section{PENDAHULUAN}

Pendidikan merupakan suatu proses interaksi belajar mengajar yang bertujuan untuk perkembangan mental menjadi mandiri dan utuh. Di mana setiap individu atau anak memiliki cara yang berbeda dalam menyerap dan mengolah informasi yang diterimanya. Berdasarkan pengalaman peneliti dan hasil wawancara dengan dosen-dosen ditemukan bahwa selama mengajar terdapat beberapa mahasiswa yang selama pembelajaran fokus memperhatikan proses pembelajaran yang diberikan, sedangkan mahasiswa yang lainnya yang berada pada diposisi belakang bermalas-malasan. Hal ini mungkin dikarenakan mahasiswa mengalami kesulitan dalam memahami pelajaran, memiliki ingatan yang buruk, sehingga informasi yang diperoleh tidak maksimal, dan mungkin ini ada kaitannya dengan gaya belajar yang diterapkan oleh mahasiswa.

Gaya belajar adalah cara yang konsisten yang dilakukan oleh seorang murid dalam melakukan stimulus atau informasi, cara mengingat, berfikir dan memecahkan soal. ${ }^{1}$ Gaya belajar merupakan ekspresi keunikan individu yang relevan dengan pendidikan. Kaitannya dengan pengajaran di kelas, gaya belajar dapat digunakan oleh guru untuk merancang model pengajaran yang efektif sebagai upaya membantu siswa belajar untuk mencapai prestasi yang tinggi. ${ }^{2}$ Gaya belajar ada tiga, yakni visual, auditori, dan kinestetik.

Seseorang yang memiliki gaya belajar visual, belajar dengan menitik beratkan ketajaman penglihatan. Seorang anak yang memunyai gaya belajar visual akan lebih mudah mengingat dengan cara melihat, misalnya membaca buku, melihat demonstrasi yang dilakukan guru, melihat contohcontoh yang tersebar di alam atau fenomena alam dengan cara observasi, bisa juga dengan melihat pembelajaran yang disajikan melalui TV atau video kaset. ${ }^{3}$ Cara yang paling tepat untuk meningkatkan hasil belajar bagi seseorang yang memunyai gaya belajar visual adalah dengan menggunakan alat bantu visual seperti grafik dan gambar.

Seseorang yang memiliki gaya belajar auditori belajar dan lebih mudah mengingat informasi dengan cara mendengarkan setiap penjelasan yang diberikan baik berupa kalimat ataupun angkaangka. Mereka menyerap makna komunikasi verbal dengan cepat tanpa harus menuangkannya dalam bentuk gambar. Mereka lebih senang mendengarkan daripada membaca. Jika akan menghadapi ujian akan lebih baik bila mereka mendengarkan orang lain, membaca bahan materi atau menulisnya sendiri kemudian membacanya dengan suara keras atau merekamnya dan memutarnya kembali. ${ }^{4}$

Seseorang yang mempunyai gaya belajar kinestetik belajar dengan cara menggerakkan otot-otot motorik mereka secara imajinatif, kreatif, mengalir, terstruktur. Mereka tidak berfikir dalam uraian kata-kata, mengumpulkan informasi secara intuitif. Gaya belajar ini bukanlah merupakan tipe pendengar yang baik karena mereka senang bergerak, dan pikiran mereka bekerja dengan sangat baik justru pada saat matanya tidak tertuju pada lawan bicara, tetapi saat yang terbaik adalah ketika ia sedang bergerak. Mereka bisa menjadi pendengar yang baik saat mata mereka tidak terfokus ke satu titik atau tidak melihat ke arah lawan bicara. Memori mereka juga lebih baik justru pada saat mereka banyak bergerak. Saat mereka bergerak mereka bisa relaks dan berkonsentrasi. ${ }^{5}$

Maka dari itu gaya belajar menjadi perlu diketahui karena kemampuan setiap anak dalam memahami materi berbeda-beda, ada yang cepat, sedang dan ada pula yang sangat lambat. Sebagian mahasiswa ada yang lebih suka mendengarkan, ada yang lebih suka membaca kemudian memahaminya, ada yang suka membentuk kelompok kemudian mendiskusikan pertanyaan-pertanyaan menyangkut materi perkuliahan. Oleh karena ini dalam proses belajar mengajar, mahasiswa perlu dibantu dan diarahkan untuk mengenali gaya belajarnya sehingga tujuan pebelajaran dapat tercapai. Ini merupakan tugas seorang pendidik yang professional dimana seorang pendidik harus mengetahui atau memahami karakteristik peserta didik, memahami perbedaan potensi, variasi gaya belajar, dan memperlakukan setiap anak sebagai pribadi yang unik dan utuh.

${ }^{1}$ S Nasution, Berbagai Pendekatan Dalam Proses Belajar Mengajar (Cetakan Kelimabelas) (Jakarta: PT Bumi Aksara, 2011).

${ }^{2}$ Popi Sopiatin and Sohari Sahrani, Psikologi Belajar Dalam Perspektif Islam (Bogor: Ghalia Indonesia, 2011).

${ }^{3}$ M Andi Setiawan, Belajar Dan Pembelajaran (Uwais Inspirasi Indonesia, 2002).

${ }^{4}$ Ricki Linksman, Cara Belajar Cepat (Semarang: Effhar dan Dahara Prize, 2004).

${ }^{5}$ Linksman. 
Maka dengan ini Pendidik harus pintar mengenali gaya belajar dan memilih gaya belajar yang sesuai agar dapat mempersiapkan strategi yang cocok untuk diajarkan agar dapat membangkitkan hasil belajar mereka. Setiap orang yang belajar akan tampak pada hasil belajarnya setelah dilaksanakan proses belajar. ${ }^{6}$ Howard Kingsley membagi tiga macam hasil belajar yaitu: keterampilan dan kebiasaan, pengetahuan dan pengertian, dan cita-cita. Hasil belajar berkaitan dengan pencapaian dalam bentuk memperoleh kemampuan sesuai dengan tujuan khusus yang direncanakan. Dengan demikian tugas utama seorang tenaga pendidik adalah merancang instrumen yang dapat mengumpulkan data tentang keberhasilan peserta didik untuk mencapai tujuan pembelajaran.

Berdasarkan latar belakang masalah yang telah diuraikan maka penulis tertarik melakukan penelitian mengenai hubungan gaya belajar dengan hasil belajar mahasiswa, yang nantinya diharapkan apabila dosen mengajar sesuai dengan gaya belajar mahasiswa maka proses pembelajaran mahasiswa menjadi lebih mudah, sehingga hasil belajar mahasiswa meningkat.

\section{METODE}

Jenis penelitian yang dilakukan adalah penelitian lapangan dengan menggunakan pendekatan kuantitatif. Penelitian kuantitatif adalah suatu proses menemukan pengetahuan yang menggunakan data berupa angka sebagai alat menemukan keterangan mengenai apa yang ingin kita ketahui yang digunakan dalam penelitian ini. ${ }^{7}$

Penelitian ini dilaksanakaan di Kampus IAIN Bone pada Program Studi Ekonomi Syariah. Populasi dalam penelitian ini adalah Mahasiswa Fakultas Ekonomi dan Bisnis Islam Program Studi Ekonomi Syariah angkatan 2017 IAIN Bone yang berjumlah 144 mahasiswa. Sampel adalah bagian dari jumlah dan karakteristik yang dimiliki oleh populasi tersebut. Bila populasi besar, dan peneliti tidak mungkin mempelajari semua yang ada pada populasi. Sampel adalah pengambilan sebagian objek untuk diselidiki yang akan mewakili populasi. ${ }^{8}$ sampel dalam penelitian ini adalah mahasiswa prodi ekonomi syariah angkatan 2017 yang berjumlah 144 mahasiswa, Teknik pengambilan sampel yang digunakan yaitu metode total sampling yaitu semua subyek yang merupakan mahasiswa prodi ekonomi syariah angkatan 2017 Fakultas Ekonomi dan Bisnis Islam IAIN Bone. ${ }^{9}$

Teknik pengumpulan data yang digunakan melalui Skala Gaya Belajar dan dokumentasi. Teknik pengumpulan data pada penelitian ini adalah skala gaya belajar dan dokumentasi. Skala gaya belajar adalah skala yang digunakan untuk menilai diri mahasiswa dan menggolongkan mahasiswa berdasarkan kecenderungan gaya belajarnya masing-masing. Dokumentasi yang digunakan adalah dengan mengumpulkan data yang berkaitan dengan hasil belajar mahasiswa yaitu nilai Ujian Akhir Semester (UAS) Mahasiswa pada semester IV Prodi Ekonomi Syariah.

Instrumen yang digunakan dalam penelitian ini adalah Skala Gaya Belajar dan dokumentasi nilai Ujian Akhir Semester (UAS) Mahasiswa pada semester IV Prodi Ekonomi Syariah. Skala Gaya Belajar menggunakan Skala Likert untuk mengukur variabel bebas yaitu kecenderungan gaya belajar mahasiswa. Skala Gaya Belajar ini dikembangkan berdasarkan variabel bebas gaya belajar yang mana memiliki tiga sub variabel yaitu gaya belajar visual, audio, dan kinesthetic. Selanjutnya masingmasing sub variabel dilihat ciri-cirinya yang telah dijelaskan pada Kajian Pustaka kemudian diringkas oleh peneliti ke dalam indikator-indikator yang akhirnya dijabarkan lagi ke dalam butir-butir pernyataan. Sementara data dokumentasi sebagai metode pengumpulan data untuk mengukur hasil belajar yaitu dengan melihat nilai Ujian Akhir Semester (UAS) pada semester IV Prodi Ekonomi Syariah IAIN Bone.

Instrumen penelitian yang baik haruslah valid dan reliabel. Validitas instrumen dalam penelitian ini dibuktikan secara isi berdasarkan judgment dari para ahli dan secara konstruk berdasarkan hasil uji coba skala kecil. Semua instrumen yang digunakan dalam penelitian ini dibuktikan validitas isinya. Hasil judgment dari para ahli dihitung menggunakan rumus Aiken untuk mendapatkan indeks validitas isi dari susunan atribut yang terbentuk. Selanjutnya, berdasarkan indeks Aiken yang diperoleh

\footnotetext{
${ }^{6}$ Ahmad Susanto, Teori Belajar Dan Pembelajaran Di Sekolah Dasar (Kencana, 2016).

${ }^{7}$ Suharsimi Arikanto, Prosedur Penelitian Suatu Pendekatan Praktek (Jakarta: Rineka Cipta, 2002).

${ }^{8}$ Saifuddin Azwar, Metode Penelitian (Yogyakarta: Pustaka Belajar, 2004).

${ }^{9}$ Djemari Mardapi, Pengukuran Penilaian Dan Evaluasi Pendidikan (Yogyakarta: Nuha Medika, 2012).
} 
dibuatlah kriteria untuk menggambarkan validitas isi dari susunan atribut yang terbentuk seperti ditunjukkan pada Tabel 2. ${ }^{10}$

Tabel 1. Kategori Indeks Validitas Isi

\begin{tabular}{cc}
\hline Indeks Aiken & Kategori Validitas Isi \\
\hline$>0,4$ & Rendah \\
$0,4-0,8$ & Sedang \\
$>0,8$ & Tinggi \\
\hline
\end{tabular}

Untuk reliabilitas instrumen dalam penelitian ini diestimasi dengan menggunakan metode internal consistency, yakni rumus Cronbach-Alpha. Suatu instrumen dikatakan reliabel jika memiliki indeks reliabilitas $\geq 0,7$. Adapun kategori dari indeks reliabilitas disajikan pada Tabel $2 .{ }^{11}$

Tabel 2. Kategori Indeks Reliabilitas

\begin{tabular}{cc}
\hline Indeks Reliabilitas & Kategori \\
\hline$>0,8$ & Sangat tinggi \\
$0,7-0,8$ & Tinggi \\
$0,3-0,6$ & Rendah \\
$<0,3$ & Sangat rendah \\
\hline
\end{tabular}

Data yang terkumpul diolah secara kuantitatif karena berwujud angka, maka teknik analisis yang digunakan adalah teknik analisis statistik paramterik. Data hasil skala gaya belajar menunjukkan data interval dan perhitungannya dibantu dengan software IBM SPSS versi 20. Uji prasyarat analisis dilakukan terlebih dahulu menggunakan uji normalitas, uji homogenitas, dan uji gradiensi bersifat homogen.

Uji normaslitas dimaksudkan untuk menguji apakah data yang diperoleh berasal dari populasi berdistribusi normal atau tidak maka digunakan uji normalitas. Uji normalitas pada penelitian ini menggunakan uji kolmogrov smirnov dan shapiro-wilk. Adapun hipotesis pengujiannya sebagai berikut:

$\mathrm{H}_{0}$ : sampel berasal dari populasi yang berdistribusi normal

$\mathrm{H}_{\mathrm{a}}$ : sampel tidak berasal dari populasi yang berdistribusi normal

Uji linearitas bertujuan untuk mengetahui apakah dua variabel mempunyai hubungan yang linear atau tidak secara signifikan. Uji linearitas dalam penelitian dilakukan dengan Test for Linearity pada taraf signifikansi 0,05 . Dua variabel dikatakan mempunyai hubungan yang linear bila signifikansi (Linearity) kurang dari 0,05. Adapun hipotesis pengujiannya sebagai berikut:

$\mathrm{H}_{0}$ : tidak terdapat hubungan yang linear antara hasil belajar dan gaya belajar mahaiswa

$\mathrm{H}_{\mathrm{a}}$ : terdapat hubungan yang linear antara hasil belajar dan gaya belajar mahaiswa

Uji heteroskedasitas dimaksudkan untuk menguji apakah dalam model regresi terjadi ketidaksamaan varians dari residual satu pengamatan ke pengamatan yang lain. Uji heteroskedasitas dalam penelitian ini dilakukan dengan mengamati grafik scatter plot melalui SPSS. Jika sebaran titiktitik dalam plot tidak menunjukkan adanya suatu pola tertentu, maka dapat dikatakan bahwa model tersebut terbebas dari asumsi heteroskedastisitas. Adapun hipotesis pengujiannya sebagai berikut:

$\mathrm{H}_{0}$ : tidak terdapat gejala heteroskedasitas pada data yang dimodelkan

$\mathrm{H}_{\mathrm{a}}$ : terdapat gejala heteroskedasitas pada data yang dimodelkan

10 Kartianom Kartianom and Djemari Mardapi, "The Utilization of Junior High School Mathematics National Examination Data: Conceptual Error Diagnosis," REiD (Research and Evaluation in Education) 3, no. 2 (2018).

${ }^{11}$ Kartianom Kartianom and Oscar Ndayizeye, "What's Wrong with the Asian and African Students' Mathematics Learning Achievement? The Multilevel PISA 2015 Data Analysis for Indonesia, Japan, and Algeria," Jurnal Riset Pendidikan Matematika 4, no. 2 (2017): 200-210. 
Uji hubungan antara variabel dependen dan independen dimaksudkan untuk mengetahui ada tidaknya hubungan antara keduanya. Variabel dependen dalam penelitian ini adalah hasil belajar mahasiswa, sementara variabel independennya adalah gaya belajar mahasiswa. Adapun hipotesis pengujiannya sebagai berikut:

$\mathrm{H}_{0}$ : tidak terdapat hubungan antara hasil belajar dan gaya belajar mahasiswa

$\mathrm{H}_{\mathrm{a}}$ : terdapat hubungan antara hasil belajar dan gaya belajar mahasiswa

\section{HASIL DAN PEMBAHASAN}

\section{Deskripsi Hasil Penelitian}

\section{Hasil Pembuktian Validitas dan Estimasi Reliabilitas Instrumen}

Berdasarkan hasil kesepakatan para ahli yang diminta untuk menilai instrumen yang digunakan dalam penelitian ini dan dianalisis menggunakan rumus Aiken diperoleh hasil bahwa Instrumen ini valid secara isi dengan indeks Aiken sebesar $0,80 .{ }^{12}$ Selanjutnya, berdasarkan hasil analisis menggunakan bantuan program bantuan IBM SPSS 20 diperoleh hasil bahwa untuk instrumen gaya belajar memiliki indeks reliabilitas sebesar 0,881 yang tergolong dalam kategori tinggi dan instrumen UAS dengan indeks reliabilitas sebesar 0,921 yang tergolong dalam kategori sangat tinggi. ${ }^{13}$

\section{Hasil Uji Asumsi}

Uji asumsi atau prasyarat yang harus terpenuhi sebelum menguji hipotesis penelitian adalah uji normalitas. Dalam uji normalitas digunakan bantuan program IBM SPSS 20. Hasil analisis menunjukkan bahwa data yang digunakan dalam penelitian ini telah terbukti berdistribusi normal. Semua variabel memiliki nilai signifikansi yang lebih besar dari nilai $\alpha=0,05$. Hasil analisis untuk uji normalitas dapat dilihat pada Tabel 3 .

Tabel 3. Hasil Uji Normalitas

\begin{tabular}{ccc}
\hline Variabel & Sig. Kolmogorov-Smirnov & Ket. \\
\hline Gaya Belajar & 0,073 & Normal \\
Hasil Belajar & 0,073 & Normal
\end{tabular}

Untuk uji asumsi linearitas, hasil Test for Linearity menunjukkan angka 0,006. Angka 0,006 ini tentunya kurang dari alpha 0,05 . Dengan demikian kita perlu menolak $\mathrm{H}_{0}$ dan menerima $\mathrm{H}_{\mathrm{a}}$. Artinya, terdapat hubungan yang linear antara hasil belajar dan gaya belajar mahaiswa.

Begitu juga dengan asumsi heteroskedasitas, Gambar 1 menunjukkan bahwa sebaran titik-titik dalam plot tidak menunjukkan adanya suatu pola tertentu. Olehnya itu, dapat dikatakan bahwa model tersebut terbebas dari asumsi heteroskedastisitas.

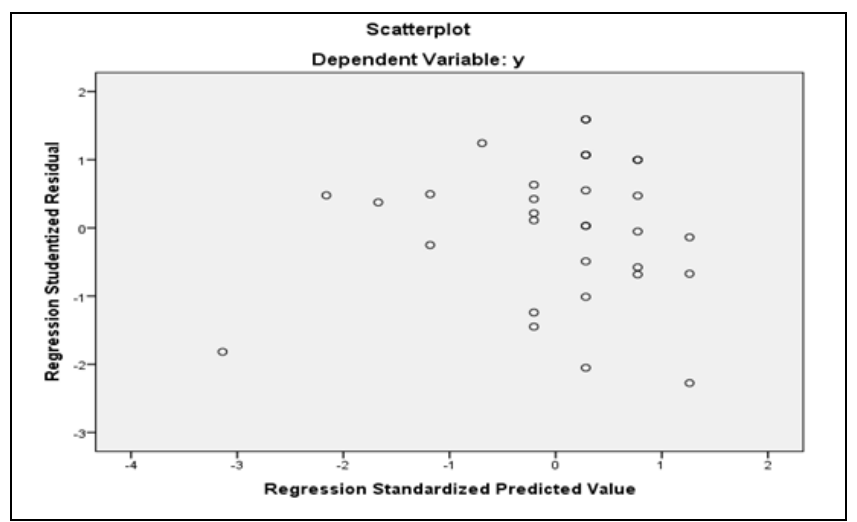

Gambar 1. Scatter-Plot Heteroskedasitas

${ }^{12}$ K Kartianom and Heri Retnawati, "Why Are Their Mathematical Learning Achievements Different? Re-Analysis Timss 2015 Data in Indonesia, Japan And Turkey," International Journal on New Trends in Education \& Their Implications (IJONTE) 9, no. 2 (2018).

${ }^{13}$ Heri Retnawati, Validitas Reliabilitas Dan Karakteristik Butir (Yogyakarta: Parama Publishing, 2016). 


\section{Hasil Uji Hipotesis Hubungan antara Gaya Belajar dan Hasil Belajar}

Hasil analisis diperoleh koefisen korelasi gaya belajar Visual terhadap hasil belajar sebesar 0,470 masuk dalam kategori sedang, Koefisien korelasi gaya belajar Audio terhadap hasil belajar sebesar 0,303 masuk kedalah kategori rendah, koefisien korelasi gaya belajar kinestetik sebesar 0,315 dan masuk kedalam kategori rendah. Koefisien korelasi gaya belajar terhadap hasil belajar sebesar 0,43 dan masuk dalam kategori sedang. Karena nilai korelasi atau $\mathrm{R} \neq 0$ maka ada hubungan yang positif dan signifikan antara gaya belajar dengan hasil belajar. Maka hipotesis diterima yaitu Ada hubungan yang positif dan signifikan antara gaya belajar yang terdiri dari gaya belajar Visual, Audio, dan Kinestetik dengan hasil belajar mahasiswa semester IV pada prodi Ekonomi Syariah IAIN Bone.

\section{Pembahasan}

Berdasarkan hasil uji hipotesis diperoleh informasi bahwa ada korelasi atau hubungan yang positif antara gaya belajar dan hasil belajar mahasiswa semester IV pada prodi Ekonomi Syariah IAIN Bone. Hasil penelitian ini sejalan dengan temuan Rijal, Syamsu, Bachtiar, \& Suhaedir bahwa ada hbungan positif antara gaya belajar dan capaian akademik peserta didik. ${ }^{14}$ Begitu juga dengan temuan dari Zahri, Yusuf, \& Muri bahwa gaya belajar mahasiswa memiliki hubungan yang positif dengan hasil belajar mahasiswa. ${ }^{15}$

Gaya belajar visual memiliki hubungan yang positif dengan hasil belajar mahasiswa. Koefisien korelasi keduanya sebesar 0,470 atau berada pada kategori sedang. Hal ini menunjukkan bahwa hbungan keduanya tidak begitu kuat. Hal ini sejalan dengan temuan dari Zahri, Yusuf, \& Muri bahwa hubungan antara gaya belajar tipe visual dan hasil belajar mahasiswa tidak begitu kuat. ${ }^{16}$

Gaya belajar audio juga memiliki hubungan yang positif dengan hasil belajar mahasiswa. Koefisien korelasi keduanya sebesar 0,303 atau berada pada kategori rendah. Hal ini menunjukkan bahwa kekuatan hubungan keduanya sangat lemah. Hal ini sejalan dengan temuan dari Zahri, Yusuf, \& Muri bahwa hubungan antara gaya belajar tipe audio dan hasil belajar mahasiswa tidak sangat lemah. ${ }^{17}$

Gaya belajar kinestetik juga memiliki hubungan yang positif dengan hasil belajar mahasiswa. Koefisien korelasi keduanya sebesar 0,315 atau berada pada kategori rendah. Hal ini menunjukkan bahwa kekuatan hubungan keduanya sangat lemah. Hal ini sejalan dengan temuan dari Zahri, Yusuf, \& Muri bahwa hubungan antara gaya belajar tipe audio dan hasil belajar mahasiswa tidak sangat lemah. ${ }^{18}$

\section{SIMPULAN}

Hasil penelitian mengenai hubungan antara gaya belajar dengan hasil belajar mahasiswa pada Program Studi Ekonomi Syariah IAIN Bone, yaitu mahasiswa Prodi Ekonomi Syariah semester IV memiliki gaya belajar yang berbeda-beda, yaitu Gaya belajar Visual sebanyak 83 mahasiswa atau $57.6 \%$, gaya belajar audio sebanyak 21 mahasiswa atau 14,6\%, sedangkan gaya belajar kinestetik sebanyak 40 mahasiswa atau 27,8\%, dan terdapat hubungan positif dan signifikan antara gaya belajar dengan hasil belajar mahasiswa pada Program Studi Ekonomi Syariah IAIN Bone, koefisien korelasi gaya belajar terhadap hasil belajar sebesar 0,43 dan masuk dalam kategori sedang.

\section{DAFTAR PUSTAKA}

Arikanto, Suharsimi. Prosedur Penelitian Suatu Pendekatan Praktek. Jakarta: Rineka Cipta, 2002. Azwar, Saifuddin. Metode Penelitian. Yogyakarta: Pustaka Belajar, 2004.

Kartianom, K, and Heri Retnawati. "Why Are Their Mathematical Learning Achievements Different?

Re-Analysis Timss 2015 Data in Indonesia, Japan And Turkey." International Journal on New

14 Syamsu Rijal and Suhaedir Bachtiar, "Hubungan Antara Sikap, Kemandirian Belajar, Dan Gaya Belajar Dengan Hasil Belajar Kognitif Siswa,” Jurnal Bioedukatika 3, no. 2 (2015): 15-20.

15 Triave Nuzila Zahri, A Muri Yusuf, and S Neviyarni, "Hubungan Gaya Belajar Dan Keterampilan Belajar Dengan Hasil Belajar Mahasiswa Serta Implikasinya Dalam Pelayanan Bimbingan Dan Konseling Di Fakultas Ilmu Pendidikan Universitas Negeri Padang," Konselor 6, no. 1 (2017): 18-23.

${ }^{16}$ Zahri, Yusuf, and Neviyarni.

${ }^{17}$ Zahri, Yusuf, and Neviyarni.

${ }^{18}$ Zahri, Yusuf, and Neviyarni. 
Trends in Education \& Their Implications (IJONTE) 9, no. 2 (2018).

Kartianom, Kartianom, and Djemari Mardapi. "The Utilization of Junior High School Mathematics National Examination Data: Conceptual Error Diagnosis." REiD (Research and Evaluation in Education) 3, no. 2 (2018).

Kartianom, Kartianom, and Oscar Ndayizeye. "What's Wrong with the Asian and African Students' Mathematics Learning Achievement? The Multilevel PISA 2015 Data Analysis for Indonesia, Japan, and Algeria." Jurnal Riset Pendidikan Matematika 4, no. 2 (2017): 200-210.

Linksman, Ricki. Cara Belajar Cepat. Semarang: Effhar dan Dahara Prize, 2004.

Mardapi, Djemari. Pengukuran Penilaian Dan Evaluasi Pendidikan. Yogyakarta: Nuha Medika, 2012. Nasution, S. Berbagai Pendekatan Dalam Proses Belajar Mengajar (Cetakan Kelimabelas). Jakarta: PT Bumi Aksara, 2011.

Retnawati, Heri. Validitas Reliabilitas Dan Karakteristik Butir. Yogyakarta: Parama Publishing, 2016. Rijal, Syamsu, and Suhaedir Bachtiar. "Hubungan Antara Sikap, Kemandirian Belajar, Dan Gaya Belajar Dengan Hasil Belajar Kognitif Siswa.” Jurnal Bioedukatika 3, no. 2 (2015): 15-20.

Setiawan, M Andi. Belajar Dan Pembelajaran. Uwais Inspirasi Indonesia, 2002.

Sopiatin, Popi, and Sohari Sahrani. Psikologi Belajar Dalam Perspektif Islam. Bogor: Ghalia Indonesia, 2011.

Susanto, Ahmad. Teori Belajar Dan Pembelajaran Di Sekolah Dasar. Kencana, 2016.

Zahri, Triave Nuzila, A Muri Yusuf, and S Neviyarni. "Hubungan Gaya Belajar Dan Keterampilan Belajar Dengan Hasil Belajar Mahasiswa Serta Implikasinya Dalam Pelayanan Bimbingan Dan Konseling Di Fakultas Ilmu Pendidikan Universitas Negeri Padang.” Konselor 6, no. 1 (2017): $18-23$. 